\title{
Alguns aspetos de transformação musical na Catedral de Évora (Portugal) no Barroco: A produção musical de Pedro Vaz Rego nas primeiras décadas do século XVIII*
}

\section{Resumo}

A Catedral de Évora foi um importante centro musical português entre os séculos XVI e XIX onde inúmeros compositores ocuparam postos no seu serviço musical produzindo repertório para uso nessa instituição. Enquanto para os séculos XVI e XVII não sobreviveu muito repertório, para as últimas décadas do século XVII e XVIII um número substancial de fontes proporcionam um vislumbre da atividade musical na Catedral, nomeadamente do compositor pedro Vaz Rego. Através de um estudo analítico da sua produção musical focando as caraterísticas de um estilo antigo predominantemente polifónico e do estilo moderno concertado, pretendeu-se identificar algumas particularidades deste compositor. No grupo de obras analisadas percebe-se que Rego foi simultaneamente autor de obras em estilo antigo, mais conservadoras, e de obras que apontam para o que se produzia nas instituições musicais portuguesas, nomeadamente a Patriarcal de Lisboa onde o estilo italiano estava implantado, influenciando-se mutuamente.

\section{Palavras-chave}

Thesaurus: catedral, música religiosa, stile concertato, instrumento musical.

Palavras-chave do autor: Pedro Vaz Rego, polifonia.

Referência bibliográfica para citar este artigo: Henriques, Luís. "Alguns aspetos de transformação musical na Catedral de Évora (Portugal) no Barroco: A produção musical de Pedro Vaz Rego nas primeiras décadas do século XVIII”. Anuario de Historia Regional y de las Fronteras 24.1 (2019): 15-33.

Luís Henriques: colaborador do pólo da Universidade de Évora (Portugal) do CESEM-Centro de Estudos de Sociologia e Estética Musical. Tem desenvolvido trabalho no estudo da polifonia vocal sacra do século XVII relacionada com a Catedral de Évora, tendo criado para o efeito o Ensemble Eborensis com quem tem realizado concertos em vários locais de Portugal e França. Gravou um CD com este grupo no âmbito do projecto FCT ORFEUS no qual foi bolseiro. Os seus interesses de investigação centram-se na polifonia vocal sacra portuguesa, com especial destaque na região do Alentejo, e a música nos Açores desde o povoamento ao início do século XX. Code ORCID: https://orcid.org/0000-0001-6533-1108. Correio eletrônico: luiscfhenriques@gmail.com.

\footnotetext{
*Este trabalho enquadra-se no âmbito do projeto de Doutoramento financiado pela FCT-Fundação para a Ciência e Tecnologia: "Polifonia portuguesa tardia: A problemática da continuidade na obra sacra de Diogo Dias Melgaz e Pedro Vaz Rego” (FCT SFRH/BD/131505/2017).
} 


\title{
Some Transformative Aspects of Music in Évora Cathedral (Portugal) in the Baroque: The Musical Production of Pedro Vaz Rego in the First Decades of the Eighteenth Century
}

\begin{abstract}
Evora Cathedral was an important Portuguese musical centre between the sixteenth and nineteenth centuries where numerous composers occupied the posts in its musical service producing repertory to be used there. While for the sixteenth and seventeenth centuries not much repertory has survived, for the last decades of the seventeenth and eighteenth century a substantial number of sources provide a glimpse of the musical activity in the Cathedral, notably the composer Pedro Vaz Rego. Through the analysis of his works, focusing the characteristics of an old style predominantly polyphonic and a modern style concertato, some particularities of this composer were identified. In the analysed works it is noticed that Rego was simultaneously author of works in a more conservative style and works that point toward what was produced in the Portuguese musical institutions, notably the Patriarcal of Lisbon where the Italian style was installed, influencing each other, placing the composer in a period of transition regarding the Évora context.
\end{abstract}

Keywords

Thesaurus: Cathedral, Religious Music, Stile Concertato, Musical Instrument. Author's keywords: Pedro Vaz Rego, Polyphony.

\section{Algunos aspectos de transformación musical en la Catedral de Évora (Portugal) en el Baroco: La producción musical de Pedro Vaz Rego en las primeras décadas del siglo XVIII}

\section{Resumen}

La Catedral de Évora fue un importante centro musical portugués entre los siglos XVI y XIX, donde numerosos compositores ocuparan puestos en su capilla musical, produciendo repertorio para uso por la institución. Mientras que de los siglos XVI y XVII, no ha sobrevivido un gran repertorio, para las últimas décadas del siglo XVII y siglo XVIII, hay un número considerable de fuentes que nos permite vislumbrar de la actividad musical en la Catedral, sobre todo del compositor, Pedro Vaz Rego. A través del análisis de sus obras, centrándose en un estilo antiguo predominantemente polifónico y de estilo moderno concertado, se identificaron algunas particularidades de este compositor. En las obras analizadas se puede percibir que Rego fue simultáneamente autor de obras en estilo más conservador y de obras que vislumbran para lo que se producia en las instituciones musicales portuguesas, en especial en la Patriarcal de Lisboa onde se había implementado el estilo italiano, influenciándose mutuamente, colocando el compositor en un periodo de transición en lo que respecta al contexto de la ciudad de Évora.

Palabras clave

Tesauro: catedral, música religiosa, stile concertato, instrumento musical.

Autor: Pedro Vaz Rego, polifonía. 


\section{Alguns aspetos de transformação musical na Catedral de Évora (Portugal) no Barroco: A produção musical de Pedro Vaz Rego nas primeiras décadas do século XVIII}

A Catedral de Évora estabeleceu-se desde as primeiras duas décadas do século XVI como um importante centro de atividade musical no que diz respeito à produção e interpretação de polifonia vocal sacra, integrada nos serviços litúrgico-musicais desta instituição conjuntamente com o repertório monódico em uso na mesma desde a Idade Média. Cada um destes repertórios passou a designar-se na organização da Catedral como cantochão, no caso do repertório monódico, e canto mensural ou canto de órgão, no caso da polifonia, permanecendo estas distinções no uso terminológico documental da Catedral até ao início do século XIX. ${ }^{1}$ As instituições criadas na cidade ao longo do século XVI, nomeadamente o Colégio dos Moços do Coro (em 1552) e a Universidade jesuíta (em 1559) enriqueceram o conhecimento dos meninos de coro ao serviço da Catedral, para além dos quatro anos de aprendizagem musical com o mestre da Claustra, assegurando mais quatro anos de estudos humanísticos, primeiramente em colégios próprios e, posteriormente na Universidade, sistema que se manteve até praticamente ao final do século XVIII. ${ }^{2}$ Para além da prática e ensino da música, a composição musical era também outra atividade que ocupava grande parte do tempo dos mestres da capela, mestres da Claustra e músicos mais importantes dentro da esfera musical da Catedral. Todavia, apesar da arte destes compositores ter sido largamente reconhecida no seu tempo, com rasgados elogios em inúmeras obras literárias, muito pouco repertório musical sobreviveu até à atualidade, resumindo-se a produção musical dos mestres com atividade em Évora entre os séculos XVI e XVII a pouco mais de uma dezena de obras, não estando uma grande percentagem destes representados. ${ }^{3}$

Em termos sociopolíticos, Évora foi cenário de algumas crises durante a primeira metade de seiscentos, nomeadamente eventos em torno na Restauração da independência portuguesa. Começou com as chamadas Alterações em 1637, prolongando-se até à década de 1660 com as campanhas militares no Alentejo contra os exércitos Castelhanos. O cerco de Évora de maio a junho de 1663 pelas tropas de D. Juan de Áustria e consequente ocupação, embora breve, causou grandes prejuízos na cidade, com a destruição do convento de Nossa Senhora do Carmo, junto à Porta da Lagoa, deixando mazelas nos de Nossa Senhora dos Remédios, à Porta de Alconchel, de Santo António da Piedade. ${ }^{4}$ Durante a segunda metade do século XVII e primeira

\footnotetext{
1 Note-se que o primeiro mestre de capela conhecido ao serviço da Catedral Mateus d'Aranda publicou dois tratados sobre música, intitulando-os Tractado de cãto llano (1533) e Tractado de cãto mensurable (1535) respetivamente.

2 José A. Alegria, História da Escola de Música da Sé de Évora (Lisboa: Fundação Calouste Gulbenkian, 1973) 52-53.

3 João P. d'Alvarenga, "Polyphonic Church Music and Sources from Late Sixteenth-Century Évora Cathedral”, Revista Portuguesa de Musicologia 2.1 (2015): 19-20.

${ }^{4}$ Luís Henriques, “A paisagem sonora de Évora no século XVII: Perspectivas a partir da actividade musical das instituições religiosas da cidade", Book of Proceedings II International Congress on Interdisciplinarity in Social and Human Sciences (Faro: Research Centre for Spatial and Organizational Dynamics, 2017) 357.
} 
do XVIII, Évora conheceu frequentes períodos de sede vacante, assumindo o Cabido a administração eclesiástica da Arquidiocese. Após o falecimento de D. Teotónio de Bragança em 1602, Évora conheceu vários arcebispos que ocuparam este cargo durante curtos períodos de tempo até à nomeação de D. José de Melo em 1611 que o ocupou até 1633. Após três anos de sede vacante, D. João Coutinho foi nomeado em 1636 permanecendo no arcebispado até 1643. A crise política e militar decorrente da Restauração fez com que Évora voltasse a ter arcebispo apenas em 1671, com a nomeação de D. Diogo de Sousa, que permaneceu até $1678 .{ }^{5}$ Este hiato implicou vinte oito anos de governo capitular da Arquidiocese que, embora mantendo o estado do serviço litúrgico-musical na Catedral como anteriormente se desenvolvia, causou alguns constrangimentos no Colégio dos Moços do Coro anexo a essa instituição. ${ }^{6}$ Após a celebração da paz entre Portugal e Espanha em 1668, só dez anos mais tarde foi nomeado D. Fr. Domingos de Gusmão para Arcebispo de Évora, permanecendo até 1689 tendo como sucessor, após três anos de sede vacante, D. Fr. Luís de Sousa, que permaneceu até 1703. A este último prelado se deve o início das obras do novo edifício para o Colégio dos Moços do Coro. No mesmo ano sucedeu-lhe D. Simão da Gama. Após a morte deste prelado iniciou-se um novo período prolongado de sede vacante, sob administração capitular, de vinte e seis anos, que corresponderam à construção da nova capela-mor da Catedral e onde se enquadra contextualmente a atividade musical de Pedro Vaz Rego. ${ }^{7}$

Também ao longo do século XVII e primeira metade do XVIII a escrita de polifonia vocal sacra continuou na Catedral de Évora pelos mestres que serviram nesta instituição durante esse período. Destes mestres de capela e da Claustra, destacam-se Manuel Rebelo e Diogo Dias Melgaz (para o século XVII) e Pedro Vaz Rego (para o XVIII) de cuja produção musical sobreviveu uma percentagem aceitável até à atualidade de forma a compreender-se o seu estilo. Aos mestres da Catedral somam-se outros que, realizando a sua aprendizagem na Claustra de Évora, desempenharam funções de mestres de capela, organistas e outros cargos musicais em outras instituições religiosas portuguesas, espanholas e do Novo Mundo. Estes compõem a maior percentagem de música impressa em Portugal na primeira metade de seiscentos, ${ }^{8}$ juntando-se largo número de obras em vários manuscritos, espalhados pelas catedrais portuguesas e espanholas. ${ }^{9}$ A produção de repertório polifónico em

\footnotetext{
${ }_{5}^{5}$ António F. Barata, Esboços Chronologico-Biographicos dos Arcebispos da Egreja de Evora (Coimbra: Imprensa Litteria, 1874) 25-41.

${ }^{6}$ José A. Alegria, O Colégio dos Moços do Coro da Sé de Évora (Lisboa: Fundação Calouste Gulbenkian, 1997) 127-128.

${ }^{7}$ Barata, Esboços 42-49.

${ }^{8}$ A impressão de música neste período concentra-se nos três compositores com atividade em Lisboa cuja aprendizagem musical se realizou na Claustra de Évora: Fr. Manuel Cardoso, Duarte Lobo e Filipe de Magalhães. Cardoso imprimiu um volume de Magnificat em 1613, três livros de missas (1625, 1636 e 1636) e ainda uma coleção em 1648; Duarte Lobo imprimiu em Antuérpia uma coleção de música para o Natal em 1602, um livro de Magnificat em 1605 e dois livros de missas (1621 e 1639); Magalhães imprimiu um livro de missas e outro de Magnificat em 1636.

${ }^{9}$ De destacar Estêvão de Brito, cuja produção musical sobrevivente encontra-se no arquivo da Catedral de Málaga, Estêvão Lopes Morago, na Catedral de Viseu, e Francisco Martins na Catedral de Elvas.
} 
Portugal continuou pelo século XVIII, com a cópia de vários livros de coro para uso em instituições religiosas portuguesas (Capela Real, catedrais e outras capelas de relevo, como Vila Viçosa), sobretudo nas décadas de 1720 e 1730. Estas iniciativas resultaram de profundas transformações ocorridas na cultura lisboeta durante os primeiros anos do reinado de D. João V. Para além da italianização geral das várias manifestações culturais, no que diz respeito à música ocorreu um corte com formas e expressões do passado, nomeadamente com a importação de cerimoniais para a Capela Real. A elevação da Capela Real à Categoria de Igreja Patriarcal em 1716 introduziu um novo corpus de repertório musical moldado no modelo romano através da importação dos livros litúrgicos e ensino, assim como músicos italianos para o serviço nesta instituição. Para além disso, o envio de compositores portugueses a Roma-António Teixeira, João Rodrigues Esteves e Francisco António de Almeida-de forma a absorverem o novo estilo de composição musical aí cultivado desde o início do século XVII, o chamado stile concertato, proporcionou a sua posterior introdução nas igrejas lisboetas ${ }^{10}$. Aqui, o equilíbrio inicial entre o repertório vocal sacro a capella e o repertório em stile concertato foi desaparecendo ao longo do século XVIII sendo o primeiro estilo gradualmente substituído pelo segundo.

Encontram-se várias fontes de importância para o contexto da Catedral eborense nos arquivos da Patriarcal em Lisboa e no Paço Ducal de Vila Viçosa. Trata-se sobretudo de coleções de música copiadas para momentos específicos do calendário litúrgico, nomeadamente a Semana Santa. No caso da Patriarcal destaca-se o Livro de Coro IX no que diz respeito ao contexto eborense. Contém este livro onze motetes para as quartas-feiras e sextas-feiras da Quaresma de Diogo Dias Melgaz (os mesmos encontrados no Códice n. ${ }^{\circ} 7$ da Catedral de Évora), copiados por António Gomes Baptista no ano de 1759, encontrando-se ainda neste manuscrito um motete de Fr. Manuel Cardoso e um responsório de Tomás Luis de Victoria. Embora uma grande parte dos estudos realizados esteja concentrada na atividade das instituições musicais lisboetas no início do século XVIII, também em outras cidades portuguesas a música vocal a capella, embora tenha coexistindo com outros repertórios até ao século XIX, foi sendo gradualmente substituída pelo stile concertato enquanto repertório primordial nos serviços litúrgico-musicais das respetivas igrejas, não sendo alheias às transformações que estavam a ocorrer na capital do reino. É este o caso da capela do Paço Ducal de Vila Viçosa, com íntimas relações com a Capela Real, onde a existência de livros de coro copiados já no século XVIII denota uma continuidade na utilização de repertório polifónico tardo-quinhentista e seiscentista até pelo menos a meados de setecentos. ${ }^{11}$

$\mathrm{Na}$ Catedral de Évora a transformação musical de um repertório maioritariamente polifónico para o concertato ocorreu praticamente ao mesmo tempo que em Lisboa, operando-se de forma mais lenta em virtude da obra de construção

10 João P. d'Alvarenga, “To Make of Lisbon a New Rome': The Repertory of the Patriarchal Church in the 1720s and 1730s”, Eighteenth-Century Music 8. 2 (2011): 179-180.

${ }^{11}$ Manuel Joaquim, Vinte Livros de Música Polifónica do Paço Ducal de Vila Viçosa (Lisboa: Fundação Casa de Bragança, 1953). Veja-se o conteúdo dos livros n. ${ }^{\circ} 8,10,15$ e 16. 
da nova capela-mor do templo eborense, que apenas terminou em $1746 .{ }^{12}$ Estas obras condicionaram em muito a atividade musical na Catedral, tendo no período de Rego e do seu sucessor Ignácio António Celestino, nomeadamente na utilização do coro-baixo, que passou temporariamente para meio da nave central. ${ }^{13}$ Também a forte tradição polifónica peninsular aí existente nas primeiras décadas de setecentos, poderá ter atrasado a implementação dos modelos romanos, como atestam os livros de coro contendo hinos de Juan Navarro copiados na primeira metade de setecentos, apesar de se encontrar também um livro de coro com missas de Giovanni Pierluigi da Palestrina. ${ }^{14}$ Esta fase de transição correspondeu à presença de Pedro Vaz Rego como mestre de capela da Catedral, consistindo a produção musical deste compositor um núcleo onde a presença de repertório segundo os modelos polifónicos partilha o mesmo espaço com um grupo de obras que aponta já para o stile concertato mais tarde praticado sistematicamente pelos compositores que o sucederam no cargo de mestre de capela.

No caso da cidade de Évora encontram-se referências à composição de polifonia com acompanhamento instrumental desde cerca de meados do século XVII, nomeadamente uma obra para o officium defunctorum que terá sido utilizada no serviço litúrgico-musical da Catedral. Trata-se do responsório Libera me para quatro vozes agudas (SSAT), com um guião de acompanhamento, de João Gomes. ${ }^{15}$ Gomes surge nas folhas de pagamento dos músicos da Catedral em 1651 como segundo organista, pressupondo-se que tenha estado ativo nesta instituição em meados do século XVII. ${ }^{16}$ Para além da obra de polifonia vocal sacra já mencionada, encontram-se mais onze obras conservadas na Biblioteca Pública de Évora compreendendo vilancicos e romances em português e castelhano deste autor que incluem um guião instrumental, possivelmente para harpa. ${ }^{17}$ Já antes de João Gomes encontram-se referências à composição de música para-litúrgica por mestres da Catedral da primeira metade do século XVII, nomeadamente Manuel Rebelo e o seu sucessor António Rodrigues Vilalva. Destes compositores não sobreviveu qualquer vilancico ou outra obra que envolvesse a participação instrumental. Porém, surgem várias obras referenciadas que, quando comparadas com obras mais tardias, pressupõem a presença de um baixo instrumental de acompanhamento. De Manuel Rebelo surgem referenciadas sete obras para quatro, seis e oito vozes no catálogo da Biblioteca Musical de D. João IV. ${ }^{18}$ De acordo com o mesmo catálogo, António Rodrigues Vilalva terá sido o autor de três vilancicos para quatro e oito vozes. ${ }^{19}$ Simultaneamente à composição de vilancicos,

\footnotetext{
${ }^{12}$ Túlio Espanca, "Fundação da Nova Capela-Mor da Catedral de Évora", A Cidade de Évora 23-24 (1951): 205.

${ }^{13}$ Luís Henriques, “A nova capela-mor setecentista da Catedral de Évora: Uma abordagem ao seu impacto na atividade musical de Pedro Vaz Rego e Ignácio António Celestino”, Arte y Patrimonio 3 (2018): 82.

${ }^{14}$ Arquivo da Sé de Évora, Fundo Musical, Códice n. ${ }^{\circ} 2$ e n. ${ }^{\circ} 1$.

${ }^{15}$ Arquivo da Sé de Évora, Fundo Musical, Diversos n. ${ }^{\circ} 45$.

${ }^{16}$ Alegria, A História da Escola 74.

${ }^{17}$ Biblioteca Pública de Évora, Fundo Musical, Cód. CLI/1-2 d n. ${ }^{\text {os }}$ 1-7, 9, 10; Cód. CLI/1-3 n. ${ }^{\circ} 11$.

${ }^{18}$ Alegria, A História da Escola 64. Nota 3.

${ }^{19}$ Alegria, A História da Escola 75. Nota 43.
} 
estes mestres foram também autores de polifonia vocal para o serviço litúrgico da Catedral. Se de João Gomes apenas se conhece o já referido responsório Libera me, de Manuel Rebelo apenas sobreviveram seis obras num livro de coro da Catedral (todas em estilo polifónico sem acompanhamento), ${ }^{20}$ não tendo sobrevivido qualquer obra no caso de Vilalva. Através da análise da produção musical destes compositores percebe-se que a escrita de música vocal a capella moldada no repertório polifónico da segunda metade do século XVI continuou ao longo do século XVII, prolongandose pelo XVIII. Ao mesmo tempo, começou também a aparecer um repertório que, embora escrito segundo um modelo polifónico, incluía já a presença de partes instrumentais específicas.

A atividade de Diogo Dias Melgaz na Catedral de Évora durante a segunda metade de seiscentos é sintomática daquilo que será o trabalho de Pedro Vaz Rego nas primeiras décadas do século XVIII. Antigo aluno do Colégio dos Moços do Coro, Melgaz começou a desempenhar funções musicais na Catedral de Évora em 1662 enquanto reitor da instituição onde havia estudado. Imediatamente após o cerco da cidade pelas tropas espanholas no âmbito da Guerra da Restauração assume também o cargo de mestre da Claustra por morte de Bento Nunes Pegado e, a partir de 1680, o de mestre de capela por morte de António Rodrigues Vilalva. É um dos compositores com atividade na Catedral dos quais sobreviveu maior quantidade de composições que se podem associar ao serviço litúrgico-musical desta instituição. Tal como os compositores que o precederam, a maior parte da produção musical de Melgaz é composta por música vocal a capella, mantendo a continuação dos modelos polifónicos da primeira metade de seiscentos. Porém, ao mesmo tempo, apesar de modelado na tradição, este repertório polifónico contém já algumas caraterísticas como um excesso de cromatismo e a escolha de intervalos ditos proibidos na tradição polifónica, como o de quarta aumentada, que apontam para um novo estilo que já estava difundido por várias instituições portuguesas, desenvolvendo-se também em Évora ao longo do século XVIII. Estas caraterísticas estão marcadamente presentes nos motetes para as quartas-feiras e sextas-feiras da Quaresma e Semana Santa a quatro vozes, que compõem uma percentagem considerável da produção de Melgaz. Há que juntar a este grupo de motetes uma série de outras obras destinadas à Semana Santa com uma funcionalidade específica. É este o caso das versões polifónicas das turbas das quatro Paixões, assim como da versão policoral dos Improperia para Sexta-Feira Santa.

Tal como os restantes compositores seiscentistas, também Diogo Dias Melgaz foi autor de vilancicos, de quatro a oito vozes, como acompanhamento instrumental, ${ }^{21}$ enquadrando-se na tendência de inclusão de partes instrumentais no repertório paralitúrgico que se vinha a acentuar já desde as primeiras décadas de seiscentos. Porém, contrariamente aos seus antecessores, sobreviveram várias obras de Melgaz para os

\footnotetext{
${ }^{20}$ Arquivo da Sé de Évora, Fundo Musical, Códice n. ${ }^{\circ} 3$.

${ }^{21}$ Biblioteca Pública de Évora, Fundo Musical, Cód. CLI/1-2 d n. ${ }^{\circ}$ 12-15. No caso do Cód. CLI/1-2 d. 15, um vilancico a quatro e oito vozes para a festa da Exaltação da Santa Cruz, a existência de várias partes com data de cópia de 1785 apontam para que esta obra tenha sido interpretada ao longo do século XVIII.
} 
serviços litúrgico-musicais que contêm partes instrumentais específicas. Trata-se de um motete policoral, Recordare, Virgo Mater, para oito vozes ${ }^{22}$ com um baixo instrumental e duas obras para o officium defunctorum, Rex tremendae majestatis para quatro vozes ${ }^{23}$ e Dies irae para oito vozes ${ }^{24}$ dispostas policoralmente, também com um baixo instrumental. De notar ainda a presença de uma Lamentação do Profeta Jeremias policoral para Quinta-Feira Santa. No caso particular desta obra, o mestre de capela da Catedral no final do século XVIII, Francisco José Perdigão, realizou uma edição "domesticada, ou reduzida ao nosso methodo de hoje". ${ }^{25}$ Este arranjo não permite descortinar quais as partes vocais ou instrumentais adicionadas por Perdigão a quando na nova edição realizada em 1822. Todavia, seguindo o modelo das restantes obras de Melgaz com acompanhamento instrumental, é de supor que a versão seiscentista tivesse dois coros perfazendo oito vozes (SSAT e SATB) com um baixo instrumental atribuído a cada coro. Perdigão terá adicionado um segundo baixo para o primeiro coro assim como uma parte específica para harpa.

Melgaz ficou incapacitado de desempenhar o cargo de mestre de capela na Catedral a partir de 1697 por motivos de saúde, sendo substituído nesse ofício por Pedro Vaz Rego. Este músico assumiu o cargo de mestre de capela da Catedral de Évora em pleno durante as duas décadas do século XVIII, tendo sido possivelmente também conduzido no cargo de mestre da Claustra que Melgaz acumulava conjuntamente com o de mestre de capela. ${ }^{26} \mathrm{~A}$ chegada de Rego aos cargos musicais da Catedral de Évora ocorreu num período em que este templo sofreu alterações significativas relativamente à sua construção como anteriormente mencionado. No início de setecentos o Arcebispo D. Fr. Luís da Silva Teles empreendeu a construção de um novo edifício para albergar o Colégio dos Moços do Coro, do qual Rego havia assumido a reitoria desde 21 de julho de 1704, sendo substituído em 1711 pelo capelão da Catedral António Rodrigues. ${ }^{27} \mathrm{~A}$ partir de 1716 iniciaram-se as demolições e consequente construção da nova capela-mor da Catedral, obra que terá condicionado o fausto dos serviços litúrgico-musicais celebrados neste templo. Para a construção, o coro capitular (instalado na capela-mor) foi transferido para o meio da nave central, tendo permanecido neste espaço até à conclusão dos trabalhos em 1746. ${ }^{28}$ As obras da capela-mor da Catedral corresponderam ao período da sua atividade enquanto mestre de capela da mesma instituição, que cessou com a sua morte em 1736, sendo substituído nesse serviço pelo Padre Ignácio António Celestino que serviu na cerimónia de sagração e, enquanto compositor, abriu uma nova fase em termos da produção de repertório musical para uso na capela.

\footnotetext{
${ }^{22}$ Arquivo da Sé de Évora, Fundo Musical, Música Mariana n. 53.

${ }^{23}$ Arquivo da Sé de Évora, Fundo Musical, Códice n. ${ }^{\circ}$ 7, ff. 59v-62r.

${ }^{24}$ Arquivo da Sé de Évora, Fundo Musical, Hinos n. ${ }^{\circ} 33$.

${ }^{25}$ Arquivo da Sé de Évora, Fundo Musical, Lamentações n. ${ }^{\circ} 11$.

${ }^{26}$ Alegria, A História da Escola, 87.

${ }^{27}$ Alegria, A História da Escola, 155.

${ }^{28}$ Espanca, Fundação 205.
} 
Pedro Vaz Rego era natural da vila de Campo Maior, filho de Manuel Vaz e Brites Lopes, onde foi batizado a 19 de março de 1673 pelo vigário Diogo Lopes. ${ }^{29} \mathrm{O}$ seu percurso musical nos anos de juventude é praticamente desconhecido. Segundo a afirmação de Diogo Barbosa Machado na sua Bibliotheca Lusitana, Rego desempenhou o cargo de mestre de capela na Catedral de Elvas antes de assumir o mesmo posto na Catedral de Évora. ${ }^{30}$ Porém, como outras afirmações, não foi possível confirmar esta afirmação de Barbosa Machado. Certo é que, em 1697, já substituía, embora de forma interina, Diogo Dias Melgaz nas funções de mestre de capela da Catedral eborense uma vez que este, doente, já não estava em condições de as desempenhar de forma condigna. ${ }^{31}$ Após a morte de Melgaz em 1700, assumiu em pleno os cargos de mestre de capela e mestre da Claustra. Uma provisão assinada pelo Arcebispo D. Simão da Gama nomeou-o reitor do Colégio dos Moços do Coro com um ordenado anual de 33480 réis, substituindo nesse cargo o padre João de Sousa Sandoval. ${ }^{32}$ Rego renunciou a este cargo de reitor em 1710 a fim de requerer uma das dez capelanias existentes na Catedral que vagara. Foi provido na mesma, abandonando assim o Colégio dos Moços do Coro onde residia para se instalar em casa própria. ${ }^{33}$ Em novembro de 1714 foi-lhe dada posse como um dos quinze bacharéis da Catedral, posto que vagara por morte do padre Lázaro Coelho Ravasco. Desta forma, tal como alguns dos seus antecessores, também Rego teve o cuidado de se posicionar favoravelmente nos vários cargos que estavam ao seu alcance na carreira eclesiástica. ${ }^{34}$ A 9 de setembro de 1729 , o Cabido aceitou o seu pedido de aposentadoria do cargo de mestre da Claustra, mantendose apenas no cargo de mestre de capela. ${ }^{35}$ Pedro Vaz Rego morreu em Évora a 8 de abril 1736, tendo sido sepultado no mosteiro cartuxo de Scala Caeli. ${ }^{36}$ A ligação dos mestres de capela da Catedral de Évora a mosteiros e conventos masculinos da cidade parece ter sido uma tendência desde o final do século XVI, onde se pode citar a título de exemplo o caso de Cosme Delgado, que deixou os seus livros de música ao mosteiro hieronimita de Santa Maria do Espinheiro, e o de Diogo Dias Melgaz, que foi sepultado no convento de carmelitas descalços de Nossa Senhora dos Remédios. ${ }^{37}$

A obra musical de Pedro Vaz Rego inclui uma diversidade de repertório litúrgico-musical que permite colocar o compositor num momento de transição entre o final de um período em que a escrita de polifonia vocal imitativa dominava a produção

\footnotetext{
${ }^{29}$ Arquivo Distrital de Portalegre, Livro de Baptizados da Matriz de Campo Maior, 1668-1678, f. 117. Transcrito em Alegria, A História da Escola 87.

${ }^{30}$ Diogo Barbosa Machado, Bibliotheca Lusitana, Tomo III (Lisboa: Ignacio Rodrigues, 1752) 624.

${ }^{31}$ Alegria, A História da Escola 79.

${ }^{32}$ Alegria, A História da Escola 89.

${ }^{33}$ Alegria, $A$ História da Escola 89.

${ }^{34}$ Sobre a estrutura e movimentações na esfera eclesiástica da Catedral de Évora, veja-se António J. Díaz Rodríguez e Ana I. López-Salazar Codes, "El cabildo catedralicio de Évora en la Edad Moderna (15471801)", Historia y Genealogía 4 (2014): 31-48.

${ }^{35}$ Alegria, A História da Escola 93.

${ }^{36}$ Alegria, A História da Escola 94.

${ }^{37}$ Luís Henriques, "A atividade litúrgico-musical no convento de Nossa Senhora dos Remédios de Évora: o seu papel na paisagem sonora da cidade durante o século XVII", Herança-Revista de História, Património e Cultura 1. 1 (2018): 87-88.
} 
musical dos compositores afetos às instituições religiosas e o início de um novo período que assenta numa escrita de grande quantidade de música em stile concertato de influência italiana. Por um lado, encontra-se na sua produção musical um grupo de obras que seguem a tradição polifónica em uso na Catedral, nomeadamente no seguimento do seu predecessor Diogo Dias Melgaz, que continuou na Catedral ao longo do século XVIII.

Por outro lado, encontra-se já um número considerável de obras que apontam para um novo estilo de composição através da utilização de diferentes texturas e a inclusão de um orgânico instrumental específico, particularmente presente em rubricas para o próprio da Missa. Desta forma, a abordagem metodológica do presente estudo assenta numa postura de divisão e análise comparativa da produção musical de Pedro Vaz Rego entre obras enquadradas no stile antico, também designado nos ciclos romanos como vero stile, e obras aproximadas a um stile pieno ou concertato. ${ }^{38}$ A presença de obras destes dois tipos na produção de Rego permite esta análise comparativa, do ponto de vista dos elementos da tradição polifónica introduzidos também nas obras “modernas". Diogo Barbosa Machado refere que Rego era autor de "duas missas de estante", assim como de textos da Paixão, hinos e motetes. Para além destas obras, que apontam para a tradição polifónica, o autor da Bibliotheca Lusitana enumera ainda uma série de obras policorais como uma missa a quatro coros e outra a dois coros, salmos a quatro coros, Lamentações do Profeta Jeremias a três coros, como também vilancicos para o Natal, Conceição e Epifania o que, em certa forma, segue a tipologia da produção musical de Melgaz, mas também dos mestres que se podem encontrar por exemplo na Patriarcal. ${ }^{39}$

Duas das obras referidas por Barbosa Machado (as duas missas de estante) que podem ser consideradas como representantes de uma continuidade da tradição polifónica são as missas para quatro vozes (SATB) sobre o hino Tantum ergo Sacramentum e Ad Omnem Tonum. Da primeira destas missas apenas sobreviveram seis fólios incluídos no volume impresso do Missarum Liber de Filipe de Magalhães, ${ }^{40}$ contendo fragmentos do Kyrie, Gloria e Credo. Em resultado do corte das letras iniciais decoradas no início de cada seção não é possível reconstituir integralmente o texto musical das duas rubricas. Porém, na análise possível verifica-se tratar-se de uma composição sobre o cantochão do respetivo verso do hino Pange lingua. Aqui, Rego utilizou uma técnica composicional cujas origens remontam ao século $\mathrm{XV}$, reconhecendo ser conhecedor da tradição. O processo sobre como escrever missas sobre um cantus firmus proveniente do repertório do cantochão surge descrita em detalhe por Pietro Cerone no início do século XVII. Baseando-se nos teóricos quinhentistas, este autor refere entre outras regras, que na composição de missas o final do Kyrie, Gloria, Credo, Sanctus, Hosanna e do terceiro Agnus Dei deveria seguir

\footnotetext{
${ }^{38}$ Alvarenga, "To Make of Lisbon a New Rome" 183.

${ }^{39}$ Barbosa Machado, Bibliotheca Lusitana 624.

${ }^{40}$ Arquivo da Sé de Évora, Fundo Musical, Livros Impressos de Polifonia n. ${ }^{\circ}$ 3. Missarum Liber cvm Antiphonis Dominicalibus in principio, et Motetto pro Defunctis in Fine... Lisboa, Ex Offinina Laurentijs Craesbeeck, 1636.
} 
a imitação da obra polifónica e consequente ordem de entrada das vozes presente no modelo, no caso de se tratar de uma missa paródia, ou, caso tratando-se de uma missa sobre um cantus firmus, a respetiva melodia. ${ }^{41}$

Dos vários fragmentos, a seção final do Gloria (Cum Sancto Spiritu), no texto “Dei Patris. Amen”, começa precisamente com um ponto de imitação característico da polifonia imitativa que pode ser encontrada nas obras dos compositores portugueses da primeira metade do século XVII. O motivo introduzido pelo soprano é imitado pelo alto, baixo e tenor respetivamente. Na repetição do mesmo texto, com que fecha a rubrica, o cantus firmus do hino surge no alto em valores rítmicos mais longos, desenvolvendo-se uma imitação sobre um motivo que é uma ornamentação das notas finais do verso do hino sobre a palavra "Amen". Através deste breve exemplo percebe-se que Rego conhecia os preceitos teóricos da polifonia imitativa praticada da Catedral desde pelo menos o início do século XVI, compreendendo em que medida estes conceitos deveriam ser explanados na composição de rubricas que compõem o ordinário da Missa.

Não surge indicação de qual a ocasião litúrgica onde poderia ser cantada esta missa. Todavia, a melodia do cantochão que lhe serve de modelo sugere que tivesse sido muito possivelmente sido escrita para a festa de Corpus Christi. Esta festividade detinha uma grande importância no mundo Ibérico possuindo, não só uma forte componente litúrgica, como também cívica especialmente no respeitante à procissão realizada nesse dia. Com especial destaque nos meios urbanos, as corporações religiosas, irmandades, e associações de ofícios participavam ativamente no cerimonial do cortejo, não sendo Évora exceção a essa prática. ${ }^{42}$

Missa Ad Omnem Tonum é um claro exercício sobre a teoria modal e ao extremo em que a sua discussão chegou ao início do século XVIII. A obra foi copiada para um livro de coro em 1731, sendo todas as rubricas para quatro vozes (SATB) à exceção do segundo Agnus Dei, que embora esteja dividido no manuscrito em dois coros de quatro vozes cada (SATB e SATB), encontra-se escrito para oito vozes. Nesta missa, cujo título identifica a forma como está construída (em todos os tons salmódicos), Rego excluiu o chamado tonus peregrinus da lista de tons em que as vozes cadenciam ao longo de cada rubrica. Tal ocorreu também na Missa super Octo Tonos de Sebastián de Vivanco um século antes. ${ }^{43}$ A composição desta missa poderá ter sido influenciada pela polémica gerada em torno da Missa Scala Aretina composta pelo então mestre de capela da Catedral de Barcelona Francisco Valls em 1702 para onze vozes, violinos, contrabaixo, trombetas, órgão, harpa e baixo instrumental. A discórdia originou no intervalo de nona não preparado na seção «miserere nobis» do Gloria. Participaram nesta discussão vários outros mestres espanhóis sendo Rego (que

\footnotetext{
${ }^{41}$ Pietro Cerone, El melopeo y maestro, Libro XII (Nápoles: Iuan Bautista Gargano y Lucrecio Nucci, Impressores, 1613) 688.

${ }^{42}$ Gabriel Pereira, Estudos Eborenses, Vol. 2 (Évora: Edições Nazareth, 1948) 240.

${ }^{43}$ Mattias Lundberg, Tonus Peregrinus: The History of a psalm-tone and its use in Polyphonic Music (Burlington: Ashgate, 2011) 102.
} 
concordava com Valls) o único estrangeiro junto com o italiano Alessandro Scarlatti, que era de opinião contrária. Esta discussão originou a publicação de obras teóricas em que cada um dos intervenientes explanava as razões porque tomava determinado lado da contenda. Rego foi autor de uma Defesa sobre a entrada da novena da Missa Scala Aretina, composta pelo Mestre Francisco Valls, obra entretanto perdida. Apenas em 1737, um ano após a morte de Rego, esta discussão teórico-musical serenou, sem antes haverem sido publicados inúmeros manuscritos e impressos sobre o assunto, destacando-se um Parecer de Gregório Portero, mestre de capela da Catedral de Granada, em $1715 .{ }^{44}$ De uma forma geral, a Missa ad Omnem Tonum foi escrita de acordo com os mesmos parâmetros que a Missa Tantum ergo Sacramentum no que respeita à incidência de pontos de imitação e extensão das seções.

O tonus peregrinus está também presente numa outra obra de Rego que segue a tradição polifónica. É este o caso do salmo Credidi propter quod locutus sum de Nono Tom para quatro vozes que sobrevive num livro de coro copiado para a Catedral de Évora no século XVIII. ${ }^{45}$ Consta também neste livro um outro salmo, Beati omnes do Sétimo Tom, também para quatro vozes. ${ }^{46}$ Ambos os salmos estão escritos numa base assente no fabordão, atribuindo a uma voz o tom salmódico, tal como as obras deste tipo podem ser encontradas na produção musical de compositores portugueses e espanhóis do século XVI e primeira metade do XVII.

Um outro grupo de repertório que surge na produção musical de Pedro Vaz Rego é aquele que se pode denominar como polifonia acompanhada com baixo instrumental, ou obras com uma textura predominantemente homofónica também com acompanhamento instrumental. É este o caso da Missa pro Defunctis para quatro vozes (SATB) e baixo instrumental. ${ }^{47} \mathrm{Em}$ geral, as várias rubricas iniciam com um breve ponto de imitação sobre apenas um motivo ou, como é o caso do início do Introitus, dissolvendo-se alguns compassos depois numa textura homofónica que funciona como elemento retórico para enfatizar o sentido de determinada passagem textual. Por norma, nestas obras o baixo instrumental tem pouca independência, geralmente dobrando o baixo vocal ou, na ausência deste, a voz mais grave da textura vocal. O instrumento, possivelmente órgão, baixão ou harpa, tem um papel de reforço da linha vocal mais grave e a realização de harmonia a partir das partes vocais, podendo em inúmeros casos a obra vocal prescindir de qualquer acompanhamento.

Na Missa pro Defunctis, Rego segue o estilo de escrita do seu predecessor Diogo Dias Melgaz, como se encontra, por exemplo, no motete Rex tremendae majestatis deste compositor, também para quatro vozes com baixo instrumental.

\footnotetext{
${ }^{44}$ Robert Stevenson (ed.), Autores Vários: Vilancicos Portugueses. Portugaliae Musica Vol. XXIX (Lisboa: Fundação Calouste Gulbenkian, 1976), XXXVI-XXXVII. Sobre esta discussão veja-se José López-Calo, "L'intervento di Alessandro Scarlatti nella controversia sulla Messa 'Scala Aretina' di Francisco Valls", Analecta Musicologica 5 (1968): 178-187.

${ }^{45}$ Lundberg, Tonus Peregrinus 197.

${ }^{46}$ Arquivo da Sé de Évora, Fundo Musical, Códice n. ${ }^{\circ}$ 5, ff. 38v-43r (Credidi) e 43v-47r (Beati omnes).

${ }^{47}$ Arquivo da Sé de Évora, Fundo Musical, Missas pro Defunctis n. ${ }^{\circ} 13$.
} 
A presença de Melgaz parece também estar presente num grupo de obras também para quatro vozes com baixo instrumental, em particular no caso de dois motetes. $\mathrm{O}$ primeiro é $O$ quam suavis para quatro vozes (SATB) com acompanhamento. ${ }^{48}$ Aqui o baixo instrumental assume um papel mais independente que, por exemplo, na Missa pro Defunctis. As vozes, por outro lado, mantêm-se numa textura predominantemente homofónica com poucas repetições textuais. O outro motete, Iste est qui ante Deus, foi escrito para quatro vozes (SATB), violinos e baixo instrumental. ${ }^{49}$ Contrariamente a $O$ quam suavis, este motete assenta em mais repetições textuais enfatizadas pela utilização de figuras rítmicas mais curtas. São providenciadas duas cópias da mesma parte de violino. É importante referir ainda a presença de composições para-litúrgicas, como os seis vilancicos para quatro vozes e baixo instrumental, ou profanas, com o tonilho para quatro vozes. ${ }^{50}$

Rego é também autor de várias obras policorais, nomeadamente três salmos, dois graduais e a música para a Novena de São José, todas para dois coros com baixo instrumental e, em alguns casos, violinos. Difere em muito esta lista daquela referida por Barbosa Machado, ${ }^{51}$ sinal de que, ou o autor da Bibliotheca Lusitana equivocouse na respetiva enumeração, ou o repertório mencionado (que existiria na Biblioteca Musical ao tempo de D. João V) perdeu-se do arquivo da Catedral de Évora. Enquanto as obras de compositores setecentistas da Catedral, como Ignácio António Celestino ou Julião Rosado Tavares, não se incluem claramente no stile concertato, aproximamse todavia deste estilo através de uma escrita policoral levada ao extremo. Neste repertório, geralmente para dois coros (SATB e SATB ou, em alguns casos, SSAT e SATB) com um baixo instrumental (podendo conter violinos, oboés e, raramente trompas), as trocas antifonais entre ambos os coros funcionam como as seções de uma obra concertata. Porém, contrariamente à hierarquia solistas-ripieno do concertato, os compositores eborenses continuam a conferir uma igual importância entre os dois coros, introduzindo passagens intermédias com duas a três vozes.

Os dois graduais policorais destinam-se a festas do comum dos Confessores ${ }^{52}$ e para festas marianas. ${ }^{53}$ Parecem tratar-se de obras de uma fase posterior da carreira de Pedro Vaz Rego ao serviço da Sé, uma vez que ambas incluem partes para o baixo instrumental e violino. Embora esta última adição possa eventualmente sugerir uma composição já assente no stile concertato, ambas as obras mantêm uma textura policoral.

Um caso particular ocorre na música que Pedro Vaz Rego escreveu para a Novena de São José a dois coros (SSAT e SATB), com uma parte de violino e baixo instrumental e que, em certa forma, sumarizam a participação destes instrumentos

\footnotetext{
${ }^{48}$ Arquivo da Sé de Évora, Fundo Musical, Diversos n. ${ }^{\circ} 177$.

${ }^{49}$ Arquivo da Sé de Évora, Fundo Musical, Diversos n. ${ }^{\circ} 175$.

${ }^{50}$ Biblioteca Pública de Évora, Fundo Musical, Cód. CLI/1-2 d n. ${ }^{\circ s} 23$ a 27 e Cód. CLI/1-5 d n. 24.

${ }^{51}$ Barbosa Machado, Bibliotheca 624.

${ }^{52}$ Arquivo da Sé de Évora, Fundo Musical, Diversos n. ${ }^{\circ} 178$.

${ }^{53}$ Arquivo da Sé de Évora, Fundo Musical, Música Mariana n. ${ }^{\circ} 88$.
} 
nas obras vocais. No respeitante ao orgânico coral do primeiro coro, embora esteja designada a respetiva parte como tenor, a utilização de uma clave F4 e o âmbito vocal apontam para que se trate de uma parte de baixo. No caso da parte de violino, as duas cópias existentes sugerem que fossem dois instrumentistas a interpretar a obra. ${ }^{54}$ Porém, durante o período em que Rego desempenhou o cargo de mestre de capela conhece-se apenas a contratação de um músico para tocar este instrumento na capela. O violinista castelhano António Bequer de Guzmán foi contratado para o serviço da Catedral a 1 de abril de 1729 com o ordenado anual de quarenta mil reis. ${ }^{55}$ Porém, em 1740, a capela da Catedral possuía cinco violinistas contratados, bem como uma viola e rabecão $0^{56}$. Relativamente ao baixo instrumental, seria realizado por um dos dois grandes órgãos existentes na Catedral, ou por algum portativo dito "de armário" ou ainda por harpa ou baixão. Este último instrumento esteve em atividade na Catedral até ao início do século XIX, como confirmam as inúmeras referências a músicos enquanto "baixão da Sé" ao longo do século XVIII. ${ }^{57}$ Poderá, assim, tratarse de uma cópia posterior a Pedro Vaz Rego (uma vez que foi o mesmo copista que realizou todas as partes), possivelmente do período do seu sucessor no cargo Ignácio António Celestino. A presença de uma parte de violino nesta obra não implicou a escrita idiomática para este instrumento. Na maioria dos casos, o instrumento, dobra a parte do soprano do primeiro coro ou do segundo conforme a situação o que, uma vez mais, pressupõe tratar-se de uma cópia posterior adaptando texto musical prévio à inclusão de um novo instrumento. Desta forma, a obra terá sido escrita para dois coros com baixo instrumental sendo posteriormente adicionada a parte de violino com material musical preexistente. De uma forma geral, a obra está estruturada seguindo uma textura policoral contrariamente ao stile concertato cuja utilização estaria já amplamente difundida nas igrejas de Lisboa no início do século XVIII. Todavia, é dada quase igual importância a ambos os coros em termos das trocas antifonais, embora sejam atribuídas mais seções corais ao primeiro coro.

Figura 1: Pedro Vaz Rego, Novena de S. José (Diversos n. ${ }^{\circ}$ 179), cc. 1-8.

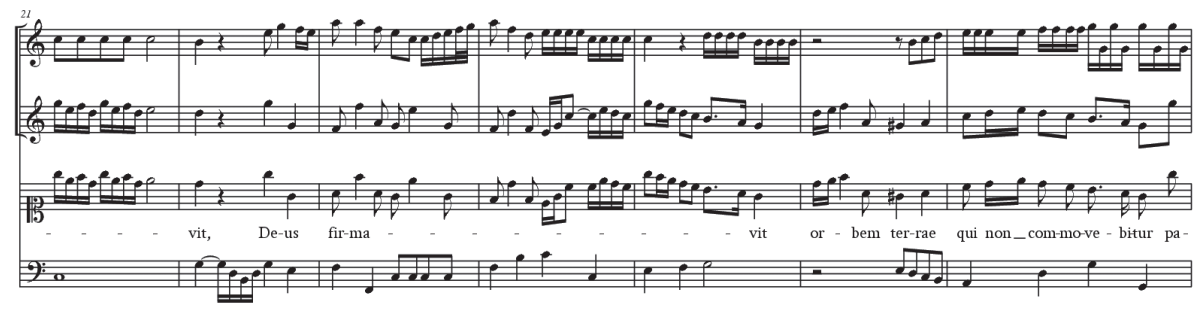

Fonte: elaboração do autor.

\footnotetext{
${ }^{54}$ Arquivo da Sé de Évora, Fundo Musical, Diversos n. ${ }^{\circ} 179$.

${ }^{55}$ Alegria, A História da Escola 93.

${ }^{56}$ Alegria, A História da Escola 98.

${ }^{57}$ Túlio Espanca, “Artes e Artistas em Évora no Século XVIII”, A Cidade de Évora 23-24 (1951): 135139. No levantamento realizado por este autor foram identificados quatro tocadores de baixão na capela da Catedral ao longo do século XVIII.
} 
A coleção de música inicia com o invitatorium Christum Dei filium, cantado enquanto era exposto o Santíssimo Sacramento, uma seção para oito vozes com trocas antifonais entre os dois coros (Figura 1). A seguir a uma oração, entoada pelo sacerdote num tom de recitação, surge o hino Veni Sancte Spiritus. A primeira estrofe inicia com um duo pelos dois sopranos do primeiro coro, seguido por uma seção a oito vozes. Rego evita colocar o hino em alternatim com estrofes em cantochão, escrevendo a segunda estrofe para oito vozes. Apenas a quarta estrofe é referida como devendo ser cantada em cantochão, não providenciando o compositor a respetiva melodia. Após uma oração surge o cântico Ave Joseph fili David finalizando a obra com a jaculatória em vernáculo Amado Jesu, Joseph, e Maria. Trata-se de uma obra marcadamente funcional, concebida para ornamentar musicalmente o serviço religioso a que se destinava.

Existe ainda no arquivo da Catedral de Évora uma obra de Pedro Vaz Rego -a cantata Deus firmavit orbem terrae - cuja escrita instrumental aponta já para épocas futuras na composição musical nesta instituição. ${ }^{58} \mathrm{Se}$, no caso da Novena de S. José a presença de duas cópias da parte de violino sugere a existência de dois instrumentistas na Catedral, a cantata de Rego destinava-se a soprano, dois violinos e baixo instrumental, exigindo desta forma a participação de dois violinistas.

Figura 2: Pedro Vaz Rego: Deus firmavit orbem terrae (Diversos n. ${ }^{\circ}$ 176), cc. 21-27.

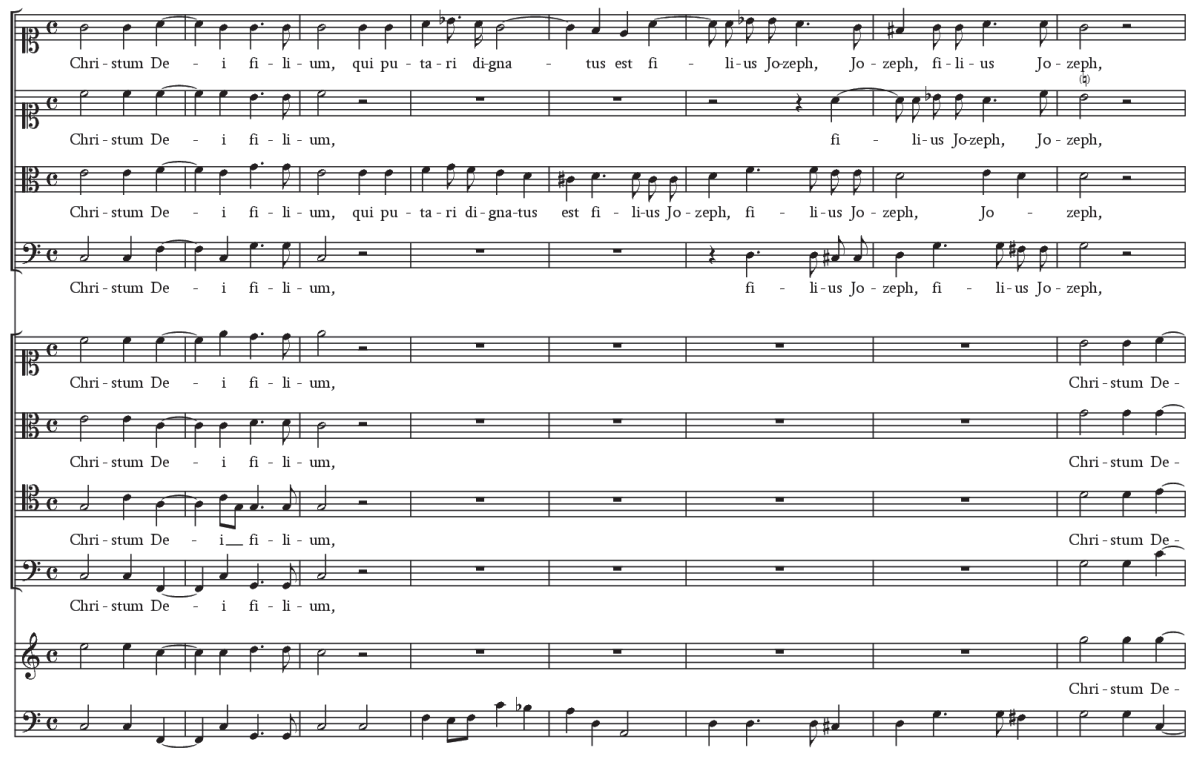

Fonte: elaboração do autor.

Embora a escrita para os dois violinos seja algo rudimentar, em várias seções com um dos instrumentos a dobrar a parte vocal e o outro com arpejos ou escalas em semicolcheias, esta cantata representa uma nova abordagem em direção a

${ }^{58}$ Arquivo da Sé de Évora, Fundo Musical, Diversos n. ${ }^{\circ} 176$. 
um tipo de escrita monódica acompanhada instrumentalmente. O sucessor de Rego, Ignácio António Celestino foi também autor de uma cantata - Cette videtis quem elegit Dominus - composta para as festividades da aclamação em Évora do Rei D. José e interpretada pela capela da Catedral a 7 de setembro de 1750, precedida por uma "bem ajustada sonata". ${ }^{59}$ Embora esta obra não tenha sobrevivido no arquivo musical da Catedral, não se conhecendo por isso o seu orgânico vocal e instrumental, a partir desta referência no livro de acordos do Cabido, percebe-se que os mestres de capela teriam também a função de escrever obras que, embora de temática religiosa, não estavam enquadradas no serviço litúrgico da Catedral. É também este o caso do tonilho Excelsa aurora Maria, "para cantar à Senhora Condessa da Ponte", para quatro vozes (SSAT), que sugere ter sido escrito para cantarem os moços do Colégio. ${ }^{60} \mathrm{O}$ texto não é litúrgico, embora a conceção vocal da obra aponte para uma textura coral homofónica, próxima das obras de polifonia com baixo instrumental. Contrariamente ao século XVII onde a obrigação de compor repertório para-litúrgico assentava na escrita de chançonetas para o Natal e vilancicos para o Ano Litúrgico, da primeira metade do século XVIII em diante estes mestres da Catedral assumem a tarefa de escrever cantatas ou outro tipo de composições semelhantes para ornamentar as cerimónias cívicas que, embora com uma forte componente religiosa, assumem outro tipo de teatralidade que não aquela do serviço litúrgico.

\section{Conclusão}

Em suma, a atividade de Pedro Vaz Rego na Catedral de Évora durante as primeiras décadas do século XVIII assume-se como um momento de transformação em termos da produção de repertório musical para uso nesta instituição. Apesar dos condicionalismos físicos, nomeadamente as obras da nova capela-mor, que terão afetado o serviço musical em termos espaciais, a introdução de novas partes instrumentais nas suas composições aponta para o abandono de formações musicais provenientes da tradição quinhentista iniciando uma fase de proximidade com os novos modelos musicais já em plena utilização nas instituições musicais de Lisboa e, em geral, por toda a Europa. Em Évora, a introdução destes modelos começa a dar alguns sinais na obra musical de Diogo Dias Melgaz, servindo Rego como ponte para compositores tardios, como é o caso de Ignácio António Celestino ou Julião Rosado Tavares, que os irão utilizar de forma sistemática. Ao mesmo tempo, existe um grupo de obras na produção musical de Rego que aponta para o passado, nomeadamente a tradição polifónica que vingou pelo menos durante dois séculos de forma sistemática na Catedral eborense. Embora escritas segundo estes parâmetros polifónicos estas obras surgem já influenciadas pelo estilo concertado e, em concreto, por uma linguagem musical já bastante afastada da modalidade polifónica. Num primeiro momento, encontram-se obras como é o caso da Novena para a festa de São José, que embora policoral, apresenta já alguns elementos que apontam para um estilo concertado, nomeadamente no que respeita à oposição entre os dois coros e o agrupamento

\footnotetext{
${ }^{59}$ Alegria, A História da Escola 100. Nota 24.

${ }^{60}$ Biblioteca Pública de Évora, Fundo Musical, Cód. CLI/1-5 d n. 24.
} 
de duas vozes. Aqui a presença de violinos, incorpora-se na textura policoral não possuindo uma identidade instrumental própria. No caso da cantata para soprano, dois violinos e contínuo, encontram-se claramente elementos que apontam para novos estilos, em concreto, o stile moderno de melodia com acompanhamento, não só no virtuosismo imprimido à voz, mas também numa escrita claramente instrumental para os instrumentos de acompanhamento, independente de quaisquer condicionalismos vocais. Desta forma, Pedro Vaz Rego surge na dinâmica musical da Catedral de Évora no início do século XVIII como um compositor de transição, constituindo-se a sua produção dois mundos musicais que se influenciaram mutuamente, como é usual acontecer com compositores que surgem em períodos de transição estilística.

\section{Bibliografia}

\section{Fontes primárias:}

\section{Manuscritos de arquivos}

Arquivo da Sé de Évora, Fundo Musical, Códice n. ${ }^{\circ} 5$.

Arquivo da Sé de Évora, Fundo Musical, Códice n. ${ }^{\circ} 8$.

Arquivo da Sé de Évora, Fundo Musical, Diversos n. ${ }^{\circ} 45$.

Arquivo da Sé de Évora, Fundo Musical, Diversos n. ${ }^{\circ} 175$.

Arquivo da Sé de Évora, Fundo Musical, Diversos n. ${ }^{\circ} 176$.

Arquivo da Sé de Évora, Fundo Musical, Diversos n. ${ }^{\circ} 177$.

Arquivo da Sé de Évora, Fundo Musical, Diversos n. ${ }^{\circ} 178$.

Arquivo da Sé de Évora, Fundo Musical, Diversos n. ${ }^{\circ} 179$.

Arquivo da Sé de Évora, Fundo Musical, Livros Impressos de Polifonia n. ${ }^{\circ} 3$.

Arquivo da Sé de Évora, Fundo Musical, Missas pro Defunctis n. ${ }^{\circ} 13$.

Arquivo da Sé de Évora, Fundo Musical, Musica Mariana n. ${ }^{\circ} 88$.

Arquivo Distrital de Portalegre, Livro de Baptizados da Matriz de Campo Maior 1668-1678.

Biblioteca Pública de Évora, Fundo Musical, Cód. CLI/1-5 d n. ${ }^{\circ} 24$.

Fábrica da Sé Patriarcal, Fundo Musical, Livro de Coro IX. 
Alguns aspetos de transformação musical na Catedral de Évora (Portugal) no Barroco: A...

\section{Fontes secundárias:}

\section{Livros}

Alegria, José A. História da Escola de Música da Sé de Évora. Lisboa: Fundação Calouste Gulbenkian, 1973.

Alegria, José A. O Colégio dos Moços do Coro da Sé de Évora. Lisboa: Fundação Calouste Gulbenkian, 1997.

Barata, António F. Esboços Chronologico-Biograhicos dos Arcebispos da Egreja de Évora. Coimbra: Imprensa Litteria, 1874.

Barbosa Machado, Diogo. Bibliotheca Lusitana. Tomo III, Lisboa: Ignacio Rodrigues, 1752.

Cerone, Pietro. El melopeo y maestro. Libro XII, Nápoles: Iuan Bautista Gargano y Lucrecio Nucci, Impressores, 1613.

Espanca, Túlio. “Artes e Artistas em Évora no Século XVIII”. A Cidade de Évora 21-22 (1950): 75-141.

Espanca, Túlio. "Fundação da Nova Capela-Mor da Catedral de Évora". A Cidade de Évora 23-24 (1951): 153-208.

Joaquim, Manuel. Vinte Livros de Música Polifónica do Paço Ducal de Vila Viçosa. Lisboa: Fundação Casa de Bragança, 1953.

Lundberg, Mattias. Tonus Peregrinus: The History of a psalm-tone and its use in Polyphonic Music. Burlington: Ashgate, 2011.

Nery, Rui V. e Castro, Paulo F. de. História da Música (Sínteses de Cultura Portuguesa). Lisboa: Europália/Imprensa Nacional-Casa da Moeda, 1992.

Pereira, Gabriel. Estudos Eborenses. Vol. 2. Évora: Edições Nazareth, 1948.

Stevenson, Robert (ed.). Autores Vários: Vilancicos Portugueses. Portugaliae Musica Vol. XXIX. Lisboa: Fundação Calouste Gulbenkian, 1976.

\section{Artigos em revistas}

Alvarenga, João P. d'. "Polyphonic Church Music and Sources from Late SixteenthCentury Évora Cathedral”. Revista Portuguesa de Musicologia 2.1 (2015): 19-40.

Alvarenga, João P. d'. “"To Make of Lisbon a New Rome': The Repertory of the Patriarchal Church in the 1720s and 1730s". Eighteenth-Century Music 8. 2 (2011): 179-214. 
Henriques, Luís. "A atividade litúrgico-musical no convento de Nossa Senhora dos Remédios de Évora: o seu papel na paisagem sonora da cidade no século XVII". Herança-Revista de História, Património e Cultura 1. 1 (2018): 73-92.

Henriques, Luís. "A nova capela-mor setecentista da Catedral de Évora: Uma abordagem ao seu impacto na atividade musical de Pedro Vaz Rego e Ignácio António Celestino". Arte y Patrimonio 3 (2018): 77-92.

López-Calo, José. "L’intervento di Alessandro Scarlatti nella controversia sulla Messa 'Scala Aretina' di Francisco Valls”. Analecta Musicologica 5 (1968): 178-200.

Rodríguez, António J. Díaz e Codes, Ana I. López-Salazar. "El cabildo catedralicio de Évora en la Edad Moderna (1547-1801)". Historia y Genealogía 4 (2014): 31-58.

\section{Teses, apresentações, documentos e outros inéditos}

Henriques, Luís. “A paisagem sonora de Évora no século XVII: Perspectivas a partir da actividade musical das instituições religiosas da cidade". Book of Proceedings II International Congress on Interdisciplinarity in Social and Human Sciences. Faro: Research Centre for Spatial and Organizational Dynamics, 2017. 